NBER WORKING PAPER SERIES

ON THE EQUIVALENCE OF PRIVATE AND PUBLIC MONEY

Markus K. Brunnermeier

Dirk Niepelt

Working Paper 25877

http://www.nber.org/papers/w25877

\author{
NATIONAL BUREAU OF ECONOMIC RESEARCH \\ 1050 Massachusetts Avenue \\ Cambridge, MA 02138 \\ May 2019
}

\begin{abstract}
For comments and discussions, we thank Ricardo Reis, an anonymous referee, Joseph Abadi, Hans Gersbach, Martin Gonzalez-Eiras, Ricardo Lagos, Sebastian Merkel, Edward Nelson, Christian Wolf, and conference and seminar participants at the Graduate Institute Geneva, the JME-SNB-SCG conference on money creation and competition, Princeton University, the Riksbank, the Universities of Chicago, Cologne, and Maryland. Brunnermeier acknowledges research support from MFM. The views expressed herein are those of the authors and do not necessarily reflect the views of the National Bureau of Economic Research.
\end{abstract}

At least one co-author has disclosed a financial relationship of potential relevance for this research. Further information is available online at http://www.nber.org/papers/w25877.ack

NBER working papers are circulated for discussion and comment purposes. They have not been peer-reviewed or been subject to the review by the NBER Board of Directors that accompanies official NBER publications.

(C) 2019 by Markus K. Brunnermeier and Dirk Niepelt. All rights reserved. Short sections of text, not to exceed two paragraphs, may be quoted without explicit permission provided that full credit, including $\odot$ notice, is given to the source. 
On the Equivalence of Private and Public Money

Markus K. Brunnermeier and Dirk Niepelt

NBER Working Paper No. 25877

May 2019

JEL No. E40,E41,E42,E44,E51,E52,E58,G21

\begin{abstract}
$\underline{\text { ABSTRACT }}$
We develop a generic model of money and liquidity that identifies sources of liquidity bubbles and seignorage rents. We provide sufficient conditions under which a swap of monies leaves the equilibrium allocation and price system unchanged. We apply the equivalence result to the "Chicago Plan," cryptocurrencies, the Indian de-monetization experiment, and Central Bank Digital Currency (CBDC). In particular, we show why CBDC need not undermine financial stability.
\end{abstract}

\author{
Markus K. Brunnermeier \\ Princeton University \\ Department of Economics \\ Bendheim Center for Finance \\ Princeton, NJ 08544 \\ and CEPR \\ and also NBER \\ markus@princeton.edu \\ Dirk Niepelt \\ Study Center Gerzensee \\ Neues Schloss \\ 3115 Gerzensee \\ Switzerland \\ and University of Bern \\ dirk.niepelt@szgerzensee.ch
}




\title{
On the Equivalence of Private and Public Money*
}

\author{
Markus K. Brunnermeier ${ }^{\dagger} \quad$ Dirk Niepelt ${ }^{\ddagger}$
}

May 22, 2019

\begin{abstract}
We develop a generic model of money and liquidity that identifies sources of liquidity bubbles and seignorage rents. We provide sufficient conditions under which a swap of monies leaves the equilibrium allocation and price system unchanged. We apply the equivalence result to the "Chicago Plan," cryptocurrencies, the Indian de-monetization experiment, and Central Bank Digital Currency (CBDC). In particular, we show why CBDC need not undermine financial stability.
\end{abstract}

Keywords: Money creation, monetary system, inside money, outside money, equivalence, CBDC, Chicago Plan, sovereign money

\section{Introduction}

Modern economies rely on public - central-bank issued - and private media of exchange. The latter are in the spotlight: FinTechs and BigTech do not only reshape the payment system as consumers increasingly bank on payment apps and mobile phones, but they also supply new digital monies; in China, the new entrants have relegated traditional banks to secondary role. This structural change occurs against the background of tightening regulation, with governments discouraging cash transactions in order to fight tax evasion and money laundering.

Whether central banks or private entities should be the principal issuers of (digital) money has been the subject of a long-standing debate. Proponents of a strong government role fear that private money creation breeds instability and shifts seignorage rents

\footnotetext{
*For comments and discussions, we thank Ricardo Reis, an anonymous referee, Joseph Abadi, Hans Gersbach, Martín Gonzalez-Eiras, Ricardo Lagos, Sebastian Merkel, Edward Nelson, Christian Wolf, and conference and seminar participants at the Graduate Institute Geneva, the JME-SNB-SCG conference on money creation and competition, Princeton University, the Riksbank, the Universities of Chicago, Cologne, and Maryland. Brunnermeier acknowledges research support from MFM.

†Princeton University; CEPR; CESifo; NBER. Princeton, NJ, 08544, USA. markus@princeton.edu, https://scholar.princeton.edu/markus.

${ }^{\ddagger}$ Study Center Gerzensee; University of Bern; CEPR; CESifo. P.O. Box 21, CH-3115 Gerzensee, Switzerland. dirk.niepelt@szgerzensee.ch, https://www.niepelt.ch.
} 
to shareholders. In the "Chicago Plan" of the 1930s and the recently rejected Swiss referendum proposal on "Vollgeld" (sovereign money), they suggest to severely restrict or even ban money creation by anyone except the central bank. Less drastic proposals aim at electronic Central Bank Digital Currency (CBDC) for use by non-banks. ${ }^{1}$ Skeptics, on the other hand, warn against the replacement of private media of exchange. In their view, a reduction of bank-issued money could undermine credit extension, with negative implications for growth; and the introduction of CBDC could encourage depositor runs and threaten financial stability.

To assess the validity of these arguments, we develop a general model of money, liquidity, and financial frictions. Within that framework, we identify sources of liquidity bubbles and seignorage rents, and we augment the standard asset pricing formula with a "liquidity kernel." Moreover, we establish conditions for the equivalence of different monetary systems. Finally, we apply our results and show how they overturn the conventional wisdom: Contrary to frequently made arguments, a swap of public for private money need not choke off credit or crowd out investment, and the introduction of CBDC need not undermine financial stability.

Our first contribution is to develop a generic framework that nests many - and most standard - models of money, liquidity, and financial frictions. We show, second, how the relaxation of means-of-payment constraints introduces "liquidity payoffs" of securities. These liquidity payoffs make bubbles on "liquid" securities - that is, securities which relax means-of-payment constraints - more likely because the standard stochastic discount factor (SDF) is augmented with a liquidity kernel that enlarges the SDF, effectively shrinking the discount rate. The liquidity payoffs generate seignorage rents for the issuers of liquid securities unless competition shifts the rents to customers.

Our framework suggests that some frequently-made arguments in the policy debate are questionable. In particular, it is unclear why the issuance of CBDC should reduce credit, crowd out investment, or undermine financial stability. Whether this would indeed be the case depends on the monetary policy accompanying the issuance of CBDC and on the strength of the central bank's commitment to serve as lender of last resort. With a strong commitment, a transfer of funds from deposit to CBDC accounts would give rise to an automatic substitution of one type of bank funding (deposits) by another one (central bank funding) - the issuance of CBDC would simply render the central bank's implicit lender-of-last-resort guarantee explicit. By construction, a swap of CBDC for deposits thus would not reduce bank funding; it would only change the composition of bank funding.

Figure 1 illustrates this "pass-through" mechanism: When households expand their CBDC ("money") holdings and lower their deposit holdings (as indicated by the arrows on the asset side of the household sector's balance sheet), then the central bank's liabilities expand correspondingly (indicated by the arrows on the liabilities side of the central bank's balance sheet). In exchange for the CBDC, the central bank acquires claims visà-vis the banking sector (indicated by the arrows on the asset side of its balance sheet). That is, the central bank automatically provides substitute funding for banks, effectively

\footnotetext{
${ }^{1}$ Monetary authorities in several countries evaluate the introduction of such "Reserves for All;" the Banco Central del Uruguay has successfully tested a CBDC.
} 

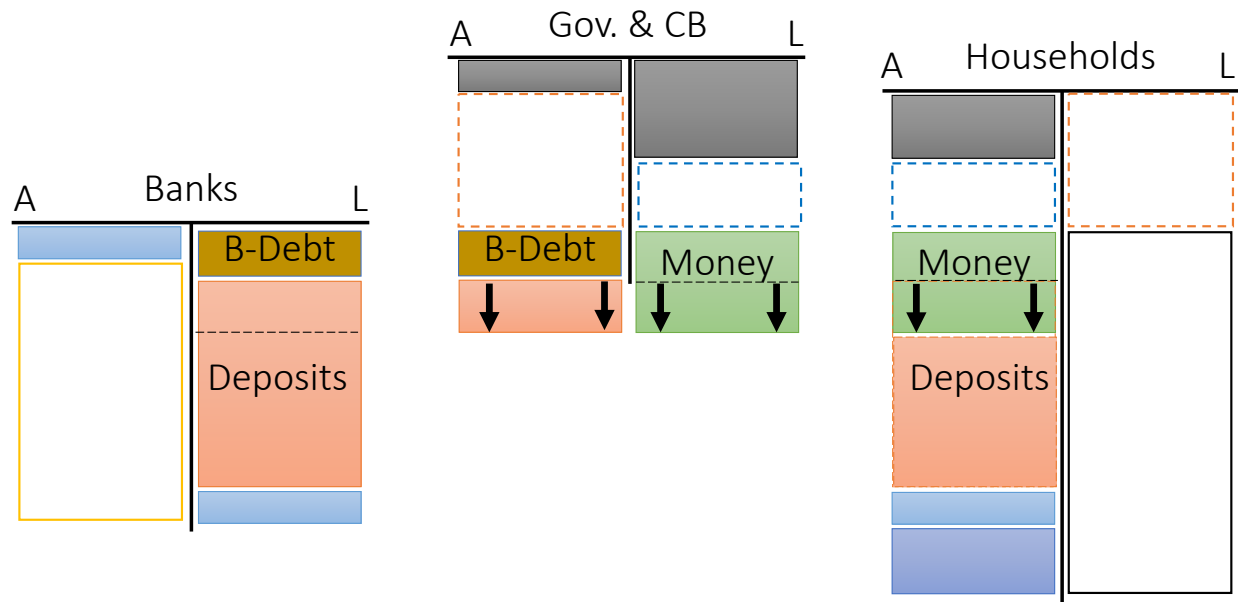

Figure 1: Pass-through funding of banks.

intermediating between non-banks and banks.

Of course, this balance sheet arithmetic does not prove that households, firms, and banks find it optimal to maintain their initial equilibrium choices rather than adjusting consumption, production, funding, or investment plans in response to the swap. After all, the swap might redistribute wealth (by shifting seignorage rents), change portfolio payoffs, and alter the liquidity services of portfolios. Our third contribution is to clarify these effects and to prove an equivalence result. We establish sufficient conditions under which a swap does not alter the equilibrium allocation and price system, even if the swap involves monies with different liquidity and payoff characteristics (e.g., due to differential run risk).

Equivalence follows from wealth and liquidity neutrality (as well as an invariant asset span); that is, it follows if the swap does not change the wealth distribution nor tighten or relax means-of-payment constraints. As long as the swap does not alter the marginal liquidity contribution of securities and the monies being swapped are minimally substitutable, liquidity neutrality follows, as we show. We argue that this requirement is met in many models, at least to the first order, but we also offer a counter example. Liquidity neutrality implies wealth neutrality, as we also show. The equivalence condition thus reduces to a simple and transparent requirement that relates to the means-of-payment constraints. In monetary models without such constraints (e.g., the standard overlapping generations (OLG) model), equivalence can always be guaranteed.

To also replicate the contingent portfolio payoffs in the equilibrium prior to the intervention the swap may have to be accompanied by contingent transfers of zero market value. These transfers are only needed if non-banks are sufficiently heterogeneous and their fiscal exposure differs from their exposure to the swap. No contingent transfers are required, for example, if the direct payoff effects of the swap are offset by indirect effects from changes in tax burdens, similarly to the offset of current and future taxes underlying the Ricardian equivalence logic (Barro 1974). 
The equivalent monetary policy that accommodates the swap completely insulates the banking sector: The central bank provides pass-through funding at the same conditions as the deposit funding by non-banks. Effectively, the central bank replicates the deposit supply schedule in the initial equilibrium, and this preserves the choice sets of banks, independently of whether they are competitive or not. By funding the banks rather than purchasing bank assets, the central bank avoids to interfere directly with the credit allocation mechanism - only banks screen and monitor investment projects.

Since a wealth- and liquidity-neutral swap in combination with the appropriate fiscalmonetary policy implies unchanged choice sets of households, firms, and banks, it also guarantees equivalence in general equilibrium. Subject to unchanged equilibrium prices, households and firms maintain their consumption and production decisions; national saving and its sectoral components remain unchanged; and there is no crowding out. A key assumption for this result is that public and private liquidity creation generates the same social costs; that is, the monies involved in the swap enter the resource constraint symmetrically. This is a weaker assumption than the usual assumption that the social cost of liquidity creation equals zero (Friedman 1969).

Our equivalence theorem constitutes a theoretical benchmark result that may or may not be plausible in specific contexts. Its main objective is to identify the key conditions for equivalence and thus, the sources of possible non-equivalence. In this sense, our research strategy is inspired by Modigliani \& Miller (1958), Barro (1974), and the many other equivalence results in the economics literature. In line with these contributions, we conduct our analysis in the context of a rather general framework; accordingly, we derive sufficient conditions for equivalence.

These conditions are easy to apply. Our fourth and final contribution is to discuss the implications of our analysis in the context of four applications. We start with two proposals for monetary reform: CBDC and the more drastic "Chicago Plan." We find that the introduction of CBDC would not change macroeconomic outcomes if it were accompanied by a pass-through policy - independently of whether deposits are subject to bank runs or not. If bank runs are a feature of the current system (and CBDC is risk free) then the equivalent fiscal-monetary policy involves state-contingent transfers between the private sector and the central bank; if it does not, for instance due to a generous deposit insurance scheme, then no such transfers are needed.

Naturally, CBDC in combination with a pass-through policy would not undermine financial stability because a depositor run into CBDC would automatically trigger passthrough funding. If the central bank did not accept bank deposits in exchange for the CBDC it issues, then equivalence would no longer be guaranteed although the run would automatically be stopped. We also argue that with pass-through funding, the introduction of CBDC could well strengthen financial stability rather than undermining it because CBDC and pass-through funding could turn the central bank into a large depositor. Unlike small depositors, such a large depositor internalizes run externalities and has the means to eliminate run equilibria.

Regarding the Chicago Plan, we also find that the conditions for equivalence are met provided that banks receive appropriate compensation for lost seignorage rents. An important motivation for the "Vollgeld" proposal, however, was that banks should relinquish 
these rents. This would transfer seignorage from bank shareholders to taxpayers, undermining wealth neutrality.

Two further applications we consider relate to the introduction of cryptocurrencies and the recent Indian de-monetization experiment. Our equivalence result does not apply to cryptocurrencies operating on blockchains with proof-of-work algorithms because these currencies require substantial resources - typically in the form of electricity - to ensure correct record keeping. In the context of other cryptocurrencies, our sufficient conditions for equivalence may well be satisfied. As for the Indian de-monetization experiment, we find that it likely violated the sufficient conditions for equivalence because some cashbased transactions at black-market prices could no longer be conducted.

Related Literature Fisher (1935) offers one of the first discussions of the Chicago plan. Gurley \& Shaw (1960) introduce the distinction between inside money issued by banks and outside money supplied by the government. ${ }^{2}$ Tobin $(1963,1969,1985)$ discusses the fractional reserve banking system and proposes a precursor to CBDC.

Wallace (1981) derives an equivalence result in a deterministic OLG economy; he shows that it is irrelevant whether households hold physical capital directly or indirectly, via their money holdings at a central bank invested in capital. Bryant (1983) summarizes important equivalence results. Chamley \& Polemarchakis (1984) establish that openmarket operations are neutral when money does not serve as a medium of exchange. Sargent $(1987,5.4)$ presents results on equivalent fiscal-monetary policies in the opposite case.

Andolfatto (2018) studies the macroeconomic consequences of banks' money creation in an OLG framework. Benes \& Kumhof (2012) set up a New Keynesian DSGE model and argue that banks' money creation ex nihilo destabilizes the economy. Faure \& Gersbach (2018) develop a model of banking and contrast the welfare under a fractional reserve banking architecture and an architecture with 100\% reserve banking. Niepelt (2018, 2020) discusses CBDC and offers an informal analysis of the conditions under which a substitution of outside for inside money does not affect macroeconomic outcomes.

Structure of Paper The remainder of the paper is organized as follows. Section 2 lays out a general model of a monetary economy with a wide range of possible monetary and other frictions. Section 3 analyzes the effects of an asset's "liquidity" on its equilibrium price. Section 4 derives and explains the main equivalence result. In Section 5, we apply our findings to Central Bank Digital Currency, the Chicago Plan, cryptocurrencies, as well as the Indian de-monetization experiment. Section 6 concludes.

\section{Model}

We consider a dynamic, stochastic economy with unit measures of possibly heterogeneous households, firms, and banks, as well as a consolidated government sector. Time is discrete and indexed by $t \geq 0$. All variables dated $t$ are measurable with respect to the history up

\footnotetext{
${ }^{2}$ Money-multiplier analysis, on which the distinction draws, dates back at least to the 1940 s.
} 
to and including date $t$, except otherwise noted. Households, firms, and banks are indexed by $h, f$, and $b$, respectively. The government does not consume nor invest; it only issues and acquires securities and collects taxes or pays transfers. We use the terms "central bank" and "government" interchangeably; a superscript $c$ denotes "central bank."

\subsection{Households}

Each household $h$ chooses consumption-leisure and portfolio sequences to maximize lifetime utility. Formally, the household maximizes

$$
\begin{aligned}
\mathcal{U}^{h}\left(x^{\cdot, h}\right) \text { s.t. } & \sum_{j} a_{t}^{j, h} p_{t}^{j}=\sum_{j} a_{t-1}^{j, h}\left(p_{t}^{j}+z_{t}^{j}\right)-\sum_{n} x_{t}^{n, h} q_{t}^{n}-\tau_{t}^{h}\left(x^{\cdot, h}, q\right) \forall t \\
& \mathcal{L}_{t}^{h}\left(\left\{a_{t}^{j, h} p_{t}^{j}\right\}_{j},\left\{a_{t-1}^{j, h}\left(p_{t}^{j}+z_{t}^{j}\right)\right\}_{j}, p, x^{\cdot, h}, q\right) \geq(=) 0 \forall t
\end{aligned}
$$

and a no-Ponzi game condition. Function $\mathcal{U}^{h}$ denotes household $h$ 's lifetime utility function which is smooth, concave, and strictly increasing (decreasing) in all arguments that generate utility (disutility). The function encompasses household $h$ 's probability filtration, which may differ across households, for instance due to asymmetric information.

We index commodities (not contingent on date or history) by $n$ and denote household $h$ 's consumption of commodity $n$ at date $t$ by $x_{t}^{n, h}$. When we omit time subscripts (e.g., $\left.x^{n, h}\right)$ then we refer to the sequence over time and histories, and when we replace the superscript $n$ by a dot (e.g., $x_{t}^{\cdot, h}$ ) then we refer to the vector containing all $n$. The price of commodity $n$ at date $t$ is denoted $q_{t}^{n} ; q_{t}$ denotes the price vector at date $t$, and $q$ denotes the price vectors at all dates. The numeraire at each date is the "first" good, $q_{t}^{1}=1$. Vector $x_{t}^{, h}$ includes, for example, consumption of goods and services, labor supply, or leisure. $^{3}$

We index securities (not contingent on date or history but possibly on the issuer) by $j$ and denote a security of type $j$ held (positive position) or issued (negative) by agent $i$ by $a_{t}^{j, i}$. As with commodities, we refer to sequences over time when we omit time subscripts and to vectors when we replace the first superscript (indicating the type of security) by a dot. For example, $a_{t}^{\cdot, h}$ denotes all security exposures of household $h$ at date $t$. The price of security $j$ at date $t$ is denoted $p_{t}^{j} ; p_{t}$ denotes the price vector at date $t$ and $p$ denotes the price vectors at all dates. Note that this formulation allows for time varying, stochastic prices of securities including monies; the stochasticity allows to capture bank runs in a reduced-form way. ${ }^{4}$ The payoff of security $j$ at date $t$, expressed in units of the numeraire, is denoted $z_{t}^{j}$.

\footnotetext{
${ }^{3}$ If we treat leisure rather than labor supply as a commodity then the budget constraint also includes a time endowment.

${ }^{4}$ To represent bank runs, let bank deposits be investor specific and let the history include information about which households and firms are first to arrive at a specific bank when this bank is subject to a run. Histories that only differ with respect to who is early in the queue and who is late, are equally likely. Ex-ante, deposits at the bank are identical but ex post, conditional on history, the payoff on deposits at the bank differs for different households and firms; households and firms in the front of the queue receive the promised payoff and price while latecomers only receive the bankruptcy value of the bank.
} 
The first constraint in the household's program represents the budget constraint. It states that the household's portfolio payoff, $\sum_{j} a_{t-1}^{j, h}\left(p_{t}^{j}+z_{t}^{j}\right)$, finances commodity purchases net of sales; tax payments net of received transfers; and securities purchases net of issuances. Function $\tau_{t}^{h}$ denotes a tax (net of transfers) function. Asset markets may be incomplete and they may also be segmented; that is, different households may have access to distinct sets of securities (to avoid unnecessary notation, we do not formalize this). The second constraint captures restrictions that relate to the medium-of-exchange function of money or other types of financial frictions that we discuss below.

This framework captures a wide variety of models of money and liquidity. ${ }^{5}$ First, overlapping generation (OLG) models à la Samuelson (1958), in which households of a certain generation, $h$ say, derive utility, $\mathcal{U}^{h}$, from consumption in specific periods. ${ }^{6}$ In such an economy no $\mathcal{L}_{t}^{h}$-constraints are present, but money may emerge in the form of a bubble if the risk-free interest rate is lower than the growth rate of the economy (Wallace 1980). ${ }^{7}$ Similar results hold in the turnpike model (Townsend 1980).

Second, models with incomplete markets à la Brunnermeier \& Sannikov (2016), where agents demand money-like assets because these assets constitute useful hedges or a safe store of value. Again, no $\mathcal{L}_{t}^{h}$-constraints are present in these models.

Third, models with a medium-of-exchange function of money that we represent by means of the $\mathcal{L}_{t}^{h}$-constraints. Our general formulation relates portfolio positions (both inherited and new), security prices, the household's commodity vector, and commodity prices to each other. A prime example of a medium-of-exchange friction that the $\mathcal{L}_{t}^{h}$ constraint captures is a cash-in-advance (CIA) constraint (Clower 1967, Grandmont \& Younes 1972, Lucas 1980, 1982, Svensson 1985, Lucas \& Stokey 1987). The literature distinguishes between two timing conventions:

Example 1 (Lucas (1982)-CIA-constraint model). Suppose households hold central bank money as medium of exchange to purchase consumption goods. Asset markets open at the beginning of the period so that households can adjust their portfolios after observing the state, just before purchasing consumption goods. The CIA constraint at date $t$ for the numeraire consumption good reads

$$
a_{t}^{M, h} p_{t}^{M} \geq x_{t}^{1, h}
$$

where we let $j=M$ denote the security index for central bank money. This CIA constraint can be represented as

$$
\mathcal{L}_{t}^{h}\left(a_{t}^{M, h} p_{t}^{M}, x_{t}^{1, h}\right) \equiv a_{t}^{M, h} p_{t}^{M}-x_{t}^{1, h} \geq 0 \forall t .
$$

Example 2 (Svensson (1985)-CIA-constraint model). Suppose alternatively that asset markets open at the end of the period so that households have to adjust their portfolios,

\footnotetext{
${ }^{5}$ In many of these models, the household and firm sectors are consolidated.

${ }^{6}$ See Shell (1971) on the interpretation of a cohort in an OLG economy as an infinitely lived household with preferences over consumption in only a few periods.

${ }^{7}$ Wallace (1981) derives an important equivalence result in a deterministic OLG setting: Central bank purchases of physical capital which are funded by money issuance do not change the equilibrium allocation.
} 
$a_{t-1}^{\cdot, h}$, in the period before they observe the state and purchase consumption goods. Since the value of central bank money at the beginning of date $t$ equals the cum-dividend-price, $p_{t}^{M}+z_{t}^{M}$, the CIA constraint can be represented as

$$
\mathcal{L}_{t}^{h}\left(a_{t-1}^{M, h}\left(p_{t}^{M}+z_{t}^{M}\right), x_{t}^{1, h}\right) \equiv a_{t-1}^{M, h}\left(p_{t}^{M}+z_{t}^{M}\right)-x_{t}^{1, h} \geq 0 \forall t .
$$

When money does not pay interest, the $z_{t}^{M}$ term equals zero. Note that money holdings chosen at date $t-1, a_{t-1}^{M, h}$, appear in several constraints at date $t$, one for each continuation history.

Another example of a model with a medium-of-exchange friction is the classic transaction cost model of Baumol (1952) and Tobin (1956) in which the household infrequently acquires stocks of low-interest bearing money to economize on a fixed acquisition cost. The $\mathcal{L}_{t}^{h}$-constraint can represent this relationship by combining a CIA constraint and a relationship between increases in money holdings and an expenditure term in the budget constraint.

A so-called shopping-time model (Saving 1971, McCallum \& Goodfriend 1987) follows when leisure constitutes one of the commodities and money holdings reduce the time it takes to purchase goods.

Example 3 (Shopping-time model). Suppose that the household has a time endowment of unity which it may consume as leisure, $x_{t}^{2, h}$, or use to purchase goods. Time spent shopping is a strictly increasing (decreasing) function, $\varphi^{h}$, of goods purchases (money holdings). This constraint can be represented as

$$
\mathcal{L}_{t}^{h}\left(a_{t}^{M, h} p_{t}^{M}, x_{t}^{1, h}, x_{t}^{2, h}\right) \equiv 1-x_{t}^{2, h}-\varphi^{h}\left(x_{t}^{1, h}, a_{t}^{M, h} p_{t}^{M}\right)=0 \forall t .
$$

Since the money-in-the-utility-function specification (Sidrauski 1967) augmented by preferences for leisure is formally equivalent to a shopping time specification (Feenstra 1986, Croushore 1993) our formulation also captures models with money in the utility function. Yet another model with a medium-of-exchange friction that the $\mathcal{L}_{t}^{h}$-constraint may represent in reduced form is a "New Monetarist" setup in the tradition of Kiyotaki \& Wright (1993) and Lagos \& Wright (2005) in which agents meet bilaterally. The friction may relate to security transactions and various securities may serve as mediums of exchange (Rocheteau \& Nosal 2017). ${ }^{8}$

Fourth, our framework captures models with incomplete markets and borrowing constraints where agents hold liquid assets as a precaution against random spending/investment needs since their future borrowing is constrained. In Bewley (1980) agents hold money (the only asset) because after a negative income shock the disposable resources do not suffice to smooth consumption. In Woodford (1990) and Kiyotaki \& Moore (2012) agents demand a safe store of value such as government bonds or money because they are borrowing constrained when an investment opportunity arises. Similarly, agents in Holmström \& Tirole (1998) hold liquid assets because the continuation of long-term investment

\footnotetext{
${ }^{8}$ Note that the liquidity constraints in these models may depend on future security prices, as these might affect the bargaining outcome. The $\mathcal{L}_{t}^{h}$-constraint includes future security prices as arguments.
} 
projects requires random funding but moral hazard frictions limit future borrowing. Our $\mathcal{L}_{t}^{h}$-constraint can represent the borrowing constraints in these models. ${ }^{9}$ In Kiyotaki \& Moore (2012), money coexists with other financial assets and physical capital both of which have limited market liquidity that is, they may only slowly be sold; this restriction can be captured by an additional $\mathcal{L}_{t}^{h}$-constraint. ${ }^{10}$ More generally, we note that the $\mathcal{L}_{t}^{h}$-constraints may be vector valued. ${ }^{11}$

\section{$2.2 \quad$ Firms}

Firms are subject to budget constraints, production possibilities sets, and medium-ofexchange constraints, $\mathcal{L}_{t}^{f}$, which parallel the $\mathcal{L}_{t}^{h}$-constraints of households. Price (or wage) setting may be constrained, for instance à la Calvo (1983), as in the prototypical "New Keynesian" model (Clarida et al. 1999, Woodford 2003, Galí 2008). In the appendix we provide a detailed description of a productive sector with a unit measure of profit maximizing, possibly heterogeneous firms.

The key objects in our equivalence result - budget constraints, medium-of-exchange restrictions, and Euler equations or asset pricing conditions - have the same structure for households and firms. As a consequence, our main results would be unchanged if we abstracted from firms altogether and considered an endowment economy instead.

\subsection{Banks}

Banks are owned by households. They choose portfolio sequences to maximize bank value or equivalently, the market value of their dividend streams (Fisher 1930). ${ }^{12}$

We allow for limited competition in the market for deposits, which are bank liabilities that enter the medium-of-exchange constraints of households and firms. To accommodate the possibility that a non-competitive bank chooses the price and payoff of its deposits we introduce an additional type of constraint, denoted by $\mathcal{C}_{t}^{b}$. This "competition constraint" reflects the equilibrium relationship between the quantity of bank b's deposits and the deposit price and rate, conditional on the choices made by other banks.

When we write $b$ for the type of security then we refer to the equity of bank $b$. E.g., $a_{t}^{b, \cdot}$ denotes bank $b$ 's shares outstanding at the end of date $t$, and $z_{t}^{b}$ denotes bank $b$ 's

\footnotetext{
${ }^{9}$ Note that while the borrowing constraint and the medium-of-exchange restriction in the Svensson (1985)-CIA-constraint model (Example 2) are very similar, the CIA constraint is tighter in states with a positive income shock whereas the reverse holds true for the borrowing constraint.

${ }^{10}$ Strictly speaking, we need to assume that dividends are paid out in the form of the asset itself in order to directly map the sales restriction in Kiyotaki \& Moore (2012) into the $\mathcal{L}_{t}^{h}$-constraint.

${ }^{11}$ Also, $\mathcal{L}_{t}^{h}$-constraints may depend on the total exposure to a given security or to components of it. For example, in an extension of Example 1 with multiple consumption goods, multiple $\mathcal{L}_{t}^{h}$-constraints could restrict the components of money holdings that are spent on different goods. We do not introduce notation to distinguish such different components but adopt the convention that a security is defined on the "component level." For instance, in the suggested extension of Example 1, we would interpret the household to hold multiple monies (all with identical risk and return characteristics), a different one for purchases of each good.

${ }^{12}$ The optimal timing of dividend payouts is indeterminate (Modigliani \& Miller 1958).
} 
dividends. Without loss of generality we normalize the total shares of each bank to unity. We denote the security index of deposits issued by bank $b$ by $j=D^{b} .{ }^{13}$

Letting $\mu_{t, s}$ denote the date- $t$ stochastic discount factor for payoffs at date $s$, bank $b$ chooses $a^{\cdot, b}, p^{D^{b}}, z^{D^{b}}$, and $z^{b}$ to maximize

$$
\begin{aligned}
\sum_{t} \mathbb{E}_{0}\left[\mu_{0, t} z_{t}^{b}\right] \quad \text { s.t. } & \sum_{j \neq b} a_{t}^{j, b} p_{t}^{j}=\sum_{j \neq b} a_{t-1}^{j, b}\left(p_{t}^{j}+z_{t}^{j}\right)-z_{t}^{b} \forall t \\
& \mathcal{C}_{t}^{b}\left(a_{t}^{\cdot, b}, p_{t}^{D^{b}}, z_{t+1}^{D^{b}}, \text { state }_{t}^{b}\right) \leq(=) 0 \forall t \\
& \mathcal{L}_{t}^{b}\left(\left\{a_{t}^{j, b} p_{t}^{j}\right\}_{j}, p\right) \geq(=) 0 \forall t
\end{aligned}
$$

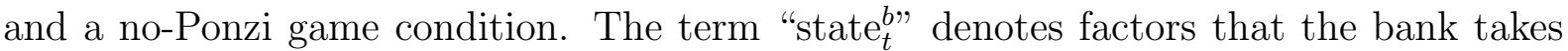
as given. When the bank is a price taker, the competition constraint $\mathcal{C}_{t}^{b}$ is not present in the program and the price of deposits, $p^{D^{b}}$, as well as their payoff, $z^{D^{b}}$, do not constitute choice variables. Banks might have access to different securities than households and firms, as in Brunnermeier \& Sannikov (2016).

The restriction $\mathcal{L}_{t}^{b}$ can represent regulatory constraints, for instance a minimum reserve requirement; restrictions implied by the functioning of interbank markets; or balance sheet restrictions that reflect incentive constraints (see, for example, Calomiris \& Kahn 1991, Diamond \& Rajan 2001). Our specification assumes that the ownership structure of the bank's liabilities is irrelevant for $\mathcal{L}_{t}^{b}$.

\subsection{Central Bank}

The central bank manages a balance sheet and collects taxes subject to the budget constraint

$$
\sum_{j \neq c} a_{t}^{j, c} p_{t}^{j}=\sum_{j \neq c} a_{t-1}^{j, c}\left(p_{t}^{j}+z_{t}^{j}\right)+\int_{h} \tau_{t}^{h}\left(x^{\cdot, h}, q\right) d h \forall t,
$$

where the security index $j=c$ denotes central bank equity, which is "owned" by tax payers. The central bank is subject to a no-Ponzi game constraint.

The model does not impose assumptions as to how central bank money comes into existence. The central bank could inject money by purchasing securities from banks or other private sector agents (open-market operations) or by transferring money and paying interest on money ("helicopter drops"). In either case money creation by the central bank implies that the consolidated government eventually transfers resources to the private sector unless the interest rate on central bank money exceeds the rate of return on central bank assets.

\subsection{Equilibrium}

In equilibrium, goods markets clear. We assume that securities do not enter resource constraints (Friedman 1969). ${ }^{14}$ Moreover, changes in the quantities of outstanding securi-

\footnotetext{
${ }^{13}$ Households may also issue deposits. We do not discuss this possibility but our analysis allows for it. At a minimum, a household may be the sole owner of a bank and thus indirectly issue deposits.

${ }^{14}$ This assumption can be relaxed; we need the securities involved in a swap to generate symmetric resource costs. Using the notation introduced in the appendix, the assumption about goods market
} 
ties reflect their payoffs as well as new issuances and redemptions, and the aggregate net demand for each security equals zero: Letting $i$ index both households and firms,

$$
\int_{i} a_{t}^{j, i} d i+\int_{b} a_{t}^{j, b} d b+a_{t}^{j, c}=0 \forall j, t .
$$

Definition 1. A competitive equilibrium conditional on the policy $\left(a^{, c},\left\{\tau^{h}\right\}_{h}\right)$ is an allocation (including $\left\{x^{\cdot, h}\right\}_{h}$ and firm production); a vector of prices and payoffs, $\left(p, q,\left\{z^{j}\right\}_{j}\right)$; a set of stochastic discount factor processes, $\left\{\mu_{0, t}^{i}\right\}_{t, i}$; and a sequence of portfolios, $\left(\left\{a^{\cdot, h}\right\}_{h}\right.$, $\left.\left\{a^{\cdot, f}\right\}_{f},\left\{a^{, b}\right\}_{b}\right)$ such that households, firms, and banks solve their programs for given policy, prices, payoffs, and stochastic discount factors; markets clear; and the stochastic discount factors reflect the optimal household and firm choices. ${ }^{15}$

A non-competitive equilibrium consists of the same objects; each non-competitive bank takes the competition constraint $\mathcal{C}_{t}^{b}$ and state $_{t}^{b}$ rather than the price and payoff of its deposits as given; and state $_{t}^{b}$ is consistent with equilibrium behavior of households, firms, and other banks.

\section{Liquidity and Value}

When analyzing the consequences of a swap - of public money for private money, say - we need to account for differences in the securities' payoffs and in their effects on $\mathcal{L}_{t^{-}}^{h}, \mathcal{L}_{t}^{f}$, and $\mathcal{L}_{t}^{b}$-constraints $\left(\mathcal{L}_{t}\right.$-constraints for short). In this section, we lay the groundwork for this.

We establish that security prices, payoffs, and effects on $\mathcal{L}_{t}$-constraints are tightly connected as the price of a security reflects its (i) fundamental payoffs; (ii) liquidity payoffs; and possibly, (iii) bubble component. An entity which creates money potentially reaps seignorage rents by issuing a security whose value primarily derives from (ii) and (iii) while generating no or only minor payoff obligations (i). Throughout, we refer to securities which enter $\mathcal{L}_{t}$-constraints as "liquid" and those which do not as "illiquid;" similarly, we refer to changes in portfolio positions or transfers that are without effect on $\mathcal{L}_{t}$-constraints as "illiquid."

Consider the portfolio choice problem of a household $h$ with exposure to security $j$ (parallel conditions apply for a firm). Let $\tilde{\mu}_{t}^{h}$ and $\tilde{\lambda}_{t}^{h}$ denote the (non-negative) Lagrange multipliers in the household's program that are attached to the date- $t$ budget constraint and $\mathcal{L}_{t}^{h}$-constraint, respectively. The Euler equation for security $a_{t}^{j, h}$ reads

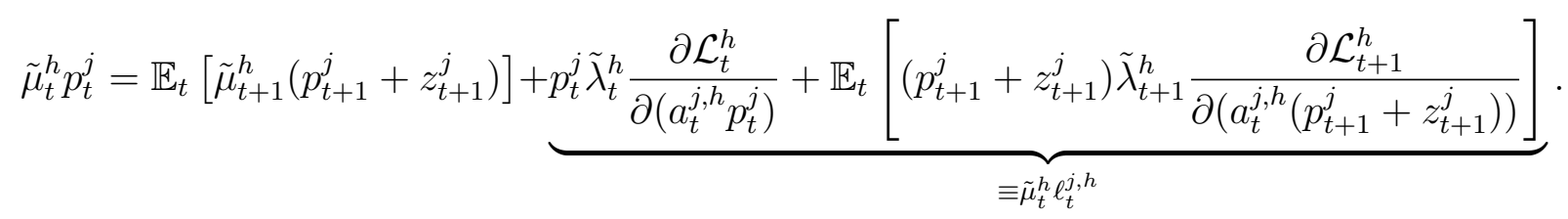

It states that the household balances costs and benefits. The costs, represented on the left-hand side, arise from the outlays for the security purchase at date $t$. The benefits,

clearing can be represented as $\int_{h} x_{t}^{, h} d h=\int_{f}\left(y_{t}^{,},{ }^{f}-i_{t}, f\right) d f \forall t$ and $\int_{f} \kappa_{t}^{f} d f=0 \forall t$ where we suppress endowments to simplify the notation.

${ }^{15}$ When markets are complete the stochastic discount factors of households and firms coincide. 
on the right-hand side, derive from the gain in purchasing power at date $t+1$ as well as from the relaxation of the $\mathcal{L}_{t}^{h}$ and $\mathcal{L}_{t+1}^{h}$-constraints. ${ }^{16}$ We denote the latter component by $\tilde{\mu}_{t}^{h} \ell_{t}^{j, h}$.

Define $\lambda_{t}^{h} \equiv \tilde{\lambda}_{t}^{h} / \tilde{\mu}_{t}^{h}$ and note that the stochastic discount factor (SDF) satisfies $\mu_{t, t+1}^{h} \equiv$ $\tilde{\mu}_{t+1}^{h} / \tilde{\mu}_{t}^{h}$. We may then write the Euler equation as $p_{t}^{j}=\mathbb{E}_{t}\left[\mu_{t, t+1}^{h}\left(p_{t+1}^{j}+z_{t+1}^{j}\right)\right]+\ell_{t}^{j, h}$ or

$$
p_{t}^{j}=\mathbb{E}_{t}\left[\mu_{t, t+1}^{h} \Lambda_{t, t+1}^{j, h}\left(p_{t+1}^{j}+z_{t+1}^{j}\right)\right]
$$

where $\Lambda_{t, t+1}^{j, h} \equiv\left(1+\lambda_{t+1}^{h} \frac{\partial \mathcal{L}_{t+1}^{h}}{\partial\left(a_{t}^{j, h}\left(p_{t+1}^{j}+z_{t+1}^{j}\right)\right)}\right) /\left(1-\lambda_{t}^{h} \frac{\partial \mathcal{L}_{t}^{h}}{\partial\left(a_{t}^{j, h} p_{t}^{j}\right)}\right)$ is the one-period "liquidity kernel." ${ }^{17}$ Iterating the Euler equation (1) forward yields

$$
p_{t}^{j}=\lim _{T \rightarrow \infty} \mathbb{E}_{t}\left[\sum_{s=1}^{T} \mu_{t, t+s}^{h} \Lambda_{t, t+s}^{j, h} z_{t+s}^{j}\right]+\lim _{T \rightarrow \infty} \mathbb{E}_{t}\left[\mu_{t, t+T}^{h} \Lambda_{t, t+T}^{j, h} p_{t+T}^{j}\right],
$$

where $\mu_{t, t+s}^{h}$ denotes the standard multi-period SDF and $\Lambda_{t, t+s}^{j, h} \equiv \prod_{\tau=t}^{t+s-1} \Lambda_{\tau, \tau+1}^{j, h}$ is the multi-period liquidity kernel.

Equation (2) indicates that the equilibrium security price has three components. First, the fundamental value reflecting the fundamental payoffs represented in the standard pricing term, $\lim _{T \rightarrow \infty} \mathbb{E}_{t}\left[\sum_{s=1}^{T} \mu_{t, t+s}^{h} z_{t+s}^{j}\right]$. Second, the liquidity payoffs, that is the liquidity value of the fundamental payoffs, $\lim _{T \rightarrow \infty} \mathbb{E}_{t}\left[\sum_{s=1}^{T} \mu_{t, t+s}^{h}\left(\Lambda_{t, t+s}^{j, h}-1\right) z_{t+s}^{j}\right]$. And third, a bubble component which is given by the last term in Equation (2).

The bubble component may differ from zero for two reasons. First, in a setting without $\mathcal{L}_{t}^{h}$-constraints $\left(\Lambda_{t, t+T}^{j, h}=1\right)$, because consumption is volatile and the shadow value of income and hence the SDF $\mu_{t, t+T}^{h}$ are convex in contingent consumption, as in the incomplete markets model of Brunnermeier \& Sannikov (2016). By Jensen's inequality, the expected value of $\mu_{t, t+T}^{h}$ then is sufficiently high for the bubble component to be bounded away from zero as $T \rightarrow \infty$. Second, in a setting with binding $\mathcal{L}_{t}^{h}$-constraints, because the standard SDF is multiplied by a liquidity kernel which exceeds unity sufficiently strongly for the bubble component to remain strictly positive in the limit.

Example 4 (Lucas (1982)-, Svensson (1985)-CIA-constraint, or shopping-time model). Consider any of the models discussed in Examples 1-3 where either $\partial \mathcal{L}_{t}^{h} / \partial\left(a_{t}^{M, h} p_{t}^{M}\right)>0$ or $\partial \mathcal{L}_{t+1}^{h} / \partial\left(a_{t}^{M, h}\left(p_{t+1}^{M}+z_{t+1}^{M}\right)\right)>0$ such that $\Lambda_{t, t+1}^{M, h}>1$. From Equation (1), the required rate of return on money, $r^{M}$ say, thus may fall short of the economy's growth rate, $g$, even if the required rate on an illiquid security, $r$ say, exceeds $g$. For instance, in a deterministic setting without inflation, we may have

$$
r^{M}=\left(\mu_{t, t+1}^{h} \Lambda_{t, t+1}^{M, h}\right)^{-1}-1<g<\left(\mu_{t, t+1}^{h}\right)^{-1}-1=r .
$$

\footnotetext{
${ }^{16}$ We assume that $a_{t}^{j, h}$ enters in at most one $\mathcal{L}_{t}^{h}$-constraint and at most one $\mathcal{L}_{t+1}^{h}$-constraint in each history. Otherwise, sums of derivatives of $\mathcal{L}_{t}^{h}$-and/or $\mathcal{L}_{t+1}^{h}$-constraints would appear in the Euler equation.

${ }^{17} \mathrm{~A}$ specific form of such a liquidity kernel also emerges in the liquidity-based asset pricing model of Holmström \& Tirole (2001) (with borrowing frictions) and in Lagos \& Wright (2005) or Lagos (2010) (with money as a medium of exchange).
} 
That is, by lowering the interest rate on money the liquidity payoff may render (deterministic and stochastic) "money bubbles" possible even outside of an OLG setting.

The partition of the security price into its three components clarifies how the creation of money entails the creation of (seignorage) rents. A central bank issuing a bubble security reaps seignorage rents because the sale of the bubble creates value without forcing the bank to produce fundamental payoffs. Similarly, a private bank earns rents by financing illiquid assets with high fundamental payoffs through the issuance of liquid inside money with low fundamental payoffs but high liquidity or bubble payoffs.

While the bank's assets and liabilities have the same market value, their fundamental values differ - illiquid assets have a higher fundamental value than liquid liabilities. The difference between the fundamental values contributes to the bank's (intangible) franchise value, which in turn is reflected in its equity market value. Competition among banks can erode this franchise value as competitive banks have incentives to issue more money and grant more loans, driving the deposit interest rate up and the loan interest rate down.

Our discussion highlights that substituting public (outside) money for private (inside) money - or vice versa - may reallocate seignorage rents and thus, redistribute wealth (in addition to possibly having inflationary or deflationary effects). To obtain neutrality of a private-public money swap, we must design the swap, or measures complementing it, so as to neutralize any wealth effects. In addition, we need to assure that the swap does not give rise to liquidity effects.

\section{Equivalence}

In this section we establish monetary equivalence classes: We derive conditions under which a swap of central bank liabilities against private bank liabilities is "irrelevant" in the sense that it does not affect the equilibrium allocation or prices - that is, the swap does not have wealth or liquidity effects nor does it affect prices in general equilibrium.

For brevity, and without pre-committing to any specific interpretation, we refer to central bank liabilities as "cash" and to bank liabilities as "deposits." Let $\Delta x$ denote the change of a generic variable $x$ relative to the initial equilibrium value and recall that $j=M$ and $j=D^{b}$, respectively, denote the security indexes denoting cash and deposits issued by bank $b$. Moreover, let $\mathbb{I}$ denote the set of households and/or firms (indexed by i) whose portfolios change as a consequence of the swap.

Definition 2. A one-period swap with agents $i \in \mathbb{I}$ at date $t$ is an exchange of cash for deposits, $\left\{\Delta a_{t}^{M, i}, \Delta a_{t}^{D^{b}, i}\right\}_{i \in \mathbb{I}}$, that is reversed after one period, in all continuation histories, such that $\Delta a_{s}^{j, i}=0, j=M, D^{b}, \forall i \in \mathbb{I}, \forall s \neq t$.

Without loss of generality we restrict attention to one-period swaps. Persistent or other, more complicated swaps can always be decomposed into elementary one-period swaps. Our notation presumes that the swap involves deposits at a single bank, $b$. The extension to the case with many banks is immediate; it only involves adjustment of notation to handle the larger set of financial institutions. With small (competitive) banks, any interesting swap necessarily involves a measure of financial institutions. 
Our approach to demonstrating equivalence is based on a comparison of choice sets. We establish that under broad conditions certain swaps (possibly accompanied by supporting measures) leave the choice sets of all private sector agents unchanged and also satisfy the government's budget constraint. The logic of the argument then is simple: If for given prices and payoffs, all agents in the private sector have the same choice sets "before" and "after" the swap then their relevant choices remain unaltered as well and the initial equilibrium allocation continues to constitute an equilibrium allocation after the swap. Our equivalence conditions can be applied without knowledge of the specific equilibrium conditions in a particular model; accordingly, they are sufficient rather than necessary. ${ }^{18}$

The swaps and supporting measures that we consider are open-market operations with transfers:

Definition 3. An open-market operation with compensating transfers with agents $i \in \mathbb{I}$ at date $t$ (conditional on a SDF and security prices and payoffs) is

1. at date $t$, an open-market operation with each $i \in \mathbb{I}$, consisting of a one-period swap as well as changes in the portfolio positions in a third, illiquid security, $j=s$,

$$
\Delta a_{t}^{s, i}=-\frac{p_{t}^{M} \Delta a_{t}^{M, i}+p_{t}^{D^{b}} \Delta a_{t}^{D^{b}, i}}{p_{t}^{s}}
$$

2. at date $t+1$, contingent, illiquid transfers to/from each $i \in \mathbb{I}$ such that the transfers together with the open-market operation leave financial wealth in all continuation histories at date $t+1$ unchanged,

$$
T_{t+1}^{i}=-\left(\left(p_{t+1}^{M}+z_{t+1}^{M}\right) \Delta a_{t}^{M, i}+\left(p_{t+1}^{D^{b}}+z_{t+1}^{D^{b}}\right) \Delta a_{t}^{D^{b}, i}+\left(p_{t+1}^{s}+z_{t+1}^{s}\right) \Delta a_{t}^{s, i}\right) .
$$

Three remarks are in order. First, an open-market operation with compensating transfers does not necessarily involve a security $s$. If the market value of agent $i$ 's swap equals zero then $\Delta a_{t}^{s, i}=0$ as well. Second, an open-market operation with compensating transfers does not necessarily involve transfers either. If the fundamental portfolio payoffs before and after the open-market operation are unchanged across all histories and for all $i \in \mathbb{I}$, that is if

$$
\left(p_{t+1}^{s}+z_{t+1}^{s}\right) \Delta a_{t}^{s, i}=-\left(\left(p_{t+1}^{M}+z_{t+1}^{M}\right) \Delta a_{t}^{M, i}+\left(p_{t+1}^{D^{b}}+z_{t+1}^{D^{b}}\right) \Delta a_{t}^{D^{b}, i}\right) \forall i \in \mathbb{I}, \forall t+1 \mid t,
$$

then there is no need for contingent transfers to offset effects on the wealth positions at date $t+1$.

Finally, we may interpret security $s$ very broadly, specifically as an implicit claim vis-àvis other agents. Consider for example an economy with a representative household. This household "owns" the government because it is the residual claimant (tax payer). Explicit changes in the household's financial position vis-à-vis the government (e.g., an increase of

\footnotetext{
${ }^{18}$ This also holds true for standard equivalence results as in Modigliani \& Miller (1958) or Barro (1974).
} 
explicit government debt) therefore are irrelevant as long as they are mirrored by changes in future taxes (Barro 1974); if the implicit government debt or assets were securitized then changes in the government's funding policy constituted open-market operations.

The same logic applies here. In a representative household economy, an open-market operation with compensating transfers need not involve an explicit ownership change of a security $s$ nor transfers because the swap necessarily involves accompanying changes in the household's implicit claims vis-à-vis the government which exactly neutralize the financial consequences of the swap. Rather than conducting an open-market operation, the central bank thus could institute the swap through lump-sum transfers (helicopter drops). The same holds true when households are heterogeneous as long as the consolidated fiscal exposure of each household (i.e., its direct exposure as well as its indirect exposure through firm ownership) mirrors its consolidated exposure to the swap. ${ }^{19}$ What matters is that the intervention leaves the wealth distribution unaltered in general equilibrium, not in partial equilibrium.

Throughout the analysis, we assume that the open-market operation leaves the asset span for all agents unchanged, i.e., it does not render markets "more or less complete."

\subsection{Wealth Neutrality}

A key element determining the choice set of a household or firm is the agent's wealth. By construction, an open-market operation with compensating transfers does not change agents' financial wealth at date $t+1$, in any history, unless they further adjust their portfolios. However, the intervention might change an agent's wealth at date $t$. This is the case if and only if the market value of the contingent transfers differs from zero. And this, in turn, is the case if and only if the swap affects total liquidity payoffs, as the following lemma shows.

Lemma 1 (Wealth Neutrality). Conditional on the SDF, security prices, and fundamental payoffs, an open-market operation with compensating transfers with agents $i \in \mathbb{I}$ at date $t$ does not change date-t financial wealth of any $i \in \mathbb{I}$ if and only if the swap does not change the liquidity payoffs of portfolios, that is if and only if for all $i \in \mathbb{I}$

$$
\ell_{t}^{M} \Delta a_{t}^{M, i}+\ell_{t}^{D^{b}} \Delta a_{t}^{D^{b}, i}=0 .
$$

Proof. The SDF, $\mu_{t, t+1}$; security prices; and fundamental payoffs imply liquidity payoffs for cash and deposits, $\ell_{t}^{M}$ and $\ell_{t}^{D^{b}}$ (recall from Section 3 the equilibrium condition $p_{t}^{j}=$ $\left.\mathbb{E}_{t}\left[\mu_{t, t+1}\left(p_{t+1}^{j}+z_{t+1}^{j}\right)\right]+\ell_{t}^{j}\right){ }^{20}$ The open-market operation with compensating transfers changes financial wealth of agent $i$ at date $t$ by

$$
p_{t}^{M} \Delta a_{t}^{M, i}+p_{t}^{D^{b}} \Delta a_{t}^{D^{b}, i}+p_{t}^{s} \Delta a_{t}^{s, i}+\mathbb{E}_{t}\left[\mu_{t, t+1} T_{t+1}^{i}\right]=\mathbb{E}_{t}\left[\mu_{t, t+1} T_{t+1}^{i}\right],
$$

\footnotetext{
${ }^{19}$ For example, wealth neutrality would hold if only a particular group paid taxes and the central bank swapped securities exclusively with that group.

${ }^{20}$ The implied liquidity payoffs are unique even if incomplete markets make the SDF non-unique.
} 
where we use the definition of an open-market operation as well as the fact that transfers are illiquid. By definition of an open-market operation with compensating transfers,

$$
\left(p_{t+1}^{M}+z_{t+1}^{M}\right) \Delta a_{t}^{M, i}+\left(p_{t+1}^{D^{b}}+z_{t+1}^{D^{b}}\right) \Delta a_{t}^{D^{b}, i}+\left(p_{t+1}^{s}+z_{t+1}^{s}\right) \Delta a_{t}^{s, i}+T_{t+1}^{i}=0 \forall t+1 \mid t .
$$

Accordingly, financial wealth changes by

$$
\begin{aligned}
\mathbb{E}_{t}\left[\mu_{t, t+1} T_{t+1}^{i}\right] & =-\sum_{j=M, D^{b}, s} \mathbb{E}_{t}\left[\mu_{t, t+1}\left(p_{t+1}^{j}+z_{t+1}^{j}\right)\right] \Delta a_{t}^{j, i} \\
& =-\sum_{j=M, D^{b}, s} p_{t}^{j} \Delta a_{t}^{j, i}+\ell_{t}^{M} \Delta a_{t}^{M, i}+\ell_{t}^{D^{b}} \Delta a_{t}^{D^{b}, i} \\
& =\ell_{t}^{M} \Delta a_{t}^{M, i}+\ell_{t}^{D^{b}} \Delta a_{t}^{D^{b}, i}
\end{aligned}
$$

where we use the fact that security $s$ is illiquid and that we consider an open-market operation.

Lemma 1 implies that an open-market operation with compensating transfers does not change agents' financial wealth if it does not alter liquidity payoffs. The market value of the contingent transfers equals zero in this case and the transfers take the form of a date- $t$ futures contract with positive and negative payoffs balancing each other across continuation histories. A setting with risk-free cash, deposits, and security $s$ constitutes a simple example where no transfers are needed at all.

\subsection{Liquidity Neutrality}

For a swap not to change the choice sets of households and firms it does not suffice that the open-market operation with compensating transfers is wealth neutral (and security prices as well as the asset span do not change). In addition, the swap must be "liquidity neutral" for any consumption-portfolio or production-portfolio plan in the choice set of a household or firm - that is, the contribution (both total and marginal) of each security to relaxing $\mathcal{L}_{t^{-}}^{i}$ and $\mathcal{L}_{t+1}^{i}$-constraints must remain the same.

Definition 4. A one-period swap with agents $i \in \mathbb{I}$ at date $t$ is liquidity neutral (conditional on commodity prices, security prices, and fundamental payoffs) if starting from any consumption-portfolio or production-portfolio plan in any agent's choice set, the swap does not change the $\mathcal{L}_{t}^{i}$ or $\mathcal{L}_{t+1}^{i}$-function values, nor the first-order derivatives.

In the appendix we state a condition, Condition 1 , that guarantees liquidity neutrality. The condition relates to the functional forms of $\mathcal{L}_{t}^{i}$ and $\mathcal{L}_{t+1}^{i}$ as well as to the relative size of $\Delta a_{t}^{M, i}$ and $\Delta a_{t}^{D^{b}, i}$. Intuitively, the condition stipulates that the isoquants of the $\mathcal{L}_{t^{-}}^{i}$ and $\mathcal{L}_{t+1^{-}}^{i}$ constraints in cash-deposit space (conditional on the quantities of other securities) must be linear, i.e., each agent's marginal rate of liquidity substitution between cash and deposits must be constant - but not necessarily equal to one, or uniform across agents; moreover, the swap must leave the total liquidity contribution of cash and deposits unchanged for each $i \in \mathbb{I}$. 
In many applications, liquidity neutrality imposes only very mild conditions. If $\left(a_{t}^{M, i}, a_{t}^{D^{b}, i}\right)$ only enters once (rather than multiple times) in the $\mathcal{L}_{t^{-}}^{i}$ and $\mathcal{L}_{t+1}^{i}$-constraints and if cash and deposits are at least minimally substitutable, which seems very plausible, then there always exists a $\Delta a_{t}^{M, i}$ for every $\Delta a_{t}^{D^{b}, i}$ such that the pair locally satisfies Condition $1 .{ }^{21}$

Example 5 (Modified Lucas (1982)-CIA-constraint or shopping-time model). Consider the model discussed in Example 1, modified to have the weighted sum of cash and deposits enter the date- $t$ CIA constraint,

$$
a_{t}^{M, h} p_{t}^{M}+a_{t}^{D^{b}, h} p_{t}^{D^{b}} v_{t}^{D^{b}} \geq x_{t}^{1, h}
$$

with "velocity" $v_{t}^{D^{b}}>0$. This model satisfies Condition 1. Similarly, the model discussed in Example 3, modified to have the weighted sum of cash and deposits enter the shoppingtime constraint, satisfies Condition 1.

When $\left(a_{t}^{M, i}, a_{t}^{D^{b}, i}\right)$ enters the $\mathcal{L}_{t}^{i}$ and/or $\mathcal{L}_{t+1}^{i}$-constraints multiple times, however, then the requirements for liquidity neutrality are strong and generically impossible to satisfy.

Example 6 (Modified Svensson (1985)-CIA-constraint model). Consider the stochastic model discussed in Example 2, modified to have the weighted sum of cash and deposits enter the CIA constraints

$$
a_{t-1}^{M, h} p_{t}^{M}+a_{t-1}^{D^{b}, h} p_{t}^{D^{b}} v_{t}^{D^{b}} \geq x_{t}^{1, h} \forall t \mid t-1
$$

with $v_{t}^{D^{b}}>0$. This imposes several constraints on cash and deposits held between dates $t-1$ and $t$ which cannot, in general, all remain satisfied after the swap. Condition 1 thus generally is violated. However, Condition 1 is satisfied if $p_{t}^{M} /\left(p_{t}^{D^{b}} v_{t}^{D^{b}}\right)$ is constant across all histories $t \mid t-1$.

To accommodate models without $\mathcal{L}_{t^{-}}^{i}$ and $\mathcal{L}_{t+1}^{i}$-constraints we adopt the convention that such models satisfy liquidity neutrality.

\subsection{Equivalence}

We can now state our main result. It holds for arbitrary combinations of open-market operations with compensating transfers, as defined in Definition 3, as long as they are both liquidity neutral, as defined in Definition 4, and "span neutral," i.e., do not change the asset span.

Theorem 1 (Equivalence). Consider an equilibrium with cash and deposits conditional on the policy $\left(a^{\cdot, c},\left\{\tau^{h}\right\}_{h}\right)$. Let there be liquidity and span neutral open-market operations with compensating transfers. The central bank can always assure that these operations implement an equilibrium with the same allocation and price system as in the initial equilibrium.

\footnotetext{
${ }^{21}$ This follows from the fact that for a small swap, the function $\mathcal{L}_{t}^{i}$ (or the function $\mathcal{L}_{t+1}^{i}$ ) can well be approximated to the first order.
} 
Proof. We prove the theorem for a single date- $t$ open-market operation with compensating transfers. The result for combinations of elementary operations follows directly.

We conjecture that the open-market operation with compensating transfers does not alter prices or fundamental payoffs. Under this conjecture, i.e., in partial equilibrium, we show that households' and firms' choice sets - and thus, their choices-remain the same. Moreover, we identify the central bank response, which conforms with the open-market operation with compensating transfers and maintains the choice sets of banks. Finally, we verify that prices remain unchanged in general equilibrium.

Partial Equilibrium Liquidity neutrality guarantees wealth neutrality in the nonbank sector because, by Lemma 1, the liquidity payoff of the swap, and thus of the open-market operation with compensating transfers, equals zero for each $i \in \mathbb{I}$, i.e., $\ell_{t}^{M} \Delta a_{t}^{M, i}+\ell_{t}^{D^{b}} \Delta a_{t}^{D^{b}, i}=0$. Since the asset span is unchanged and due to liquidity neutrality, the consumption-portfolio and production-portfolio plans of households and firms in the initial equilibrium remain budget feasible and consistent with the $\mathcal{L}_{t^{-}}^{i}$ and $\mathcal{L}_{t+1^{-}}^{i}$ constraints. Hence, the effective choice sets of households and firms do not shrink.

Nor are these choice sets enlarged as a consequence of the compensating transfers. This follows from the fact that each contingent transfer replicates a specific cash-deposit portfolio (which households and firms can purchase); and that, due to liquidity neutrality, the transfer can be undone by shorting the replicating cash-deposit portfolio without affecting the $\mathcal{L}_{t^{-}}^{i}$ and $\mathcal{L}_{t+1}^{i}$-constraints. Households and firms thus face the same effective choice sets over consumption and production plans. Hence, maintaining the original choices (except for cash, deposits, and security $s$ ) remains optimal for them.

Turning to banks, suppose first that the swap involves cash issuance in exchange for deposits. The central bank acquires claims vis-à-vis the banking sector in this case ${ }^{22}$ and the funds transferred from deposits into cash are immediately passed through back to banks. By providing the pass-through funding at the conditions of the deposit funding prior to the swap - that is, by replicating the initial deposit supply schedule - the central bank assures that the choice sets of private banks are unaltered. ${ }^{23}$ Hence, the initial equilibrium choices of banks remain optimal. In the opposite case, in which the swap involves cash redemptions in exchange for deposits, the central bank issues deposit-like claims to households and firms, thereby also insulating banks from the swap.

The central bank serves as counterparty of banks and non-banks, and it pays or receives contingent transfers at date $t+1$ whose date- $t$ market value equals zero. Since the swap must be liquidity neutral, its market price may differ from zero; in this case, the central bank also gives/receives security $s$ to/from households and firms in order to ensure wealth neutrality.

General Equilibrium The unchanged consumption and production plans remain feasible since portfolio changes do not affect resource constraints. Since all security positions except those for cash, deposits, and security $s$ are unchanged, and since the markets

\footnotetext{
${ }^{22} \mathrm{By}$ assumption, the central bank must not back monetary liabilities with gold or other commodities.

${ }^{23}$ By assumption, the ownership structure of deposits does not affect $\mathcal{L}_{t}^{b}$-constraints.
} 
for cash, deposits, and security $s$ clear, all securities markets continue to clear. Due to unchanged multipliers in the programs of households and firms as well as liquidity neutrality (the derivatives of the $\mathcal{L}_{t}^{i}$ and $\mathcal{L}_{t+1}^{i}$-constraints are unchanged), the security prices in the initial equilibrium continue to constitute equilibrium prices. The initial commodity prices, too, continue to clear markets at the unchanged marginal rates of substitution. We have verified the initial conjecture, determined the central bank response, and proved the result.

Example 7 (Modified Lucas (1982)-CIA-constraint model). Consider the model discussed in Example 5. Without loss of generality, let $p_{t}^{M}=p_{t}^{D^{b}}$. The CIA constraint at date $t$ reads

$$
a_{t}^{M, h}+a_{t}^{D^{b}, h} v_{t}^{D^{b}} \geq x_{t}^{1, h} / p_{t}^{M}
$$

with $v_{t}^{D^{b}}>0$. Let $\Delta a_{t}^{M, h}>0$. Liquidity neutrality requires $\Delta a_{t}^{D^{b}, h}=-\Delta a_{t}^{M, h} / v_{t}^{D^{b}}$. If $v_{t}^{D^{b}} \neq 1$ the swap is accompanied by transactions in security $s$, namely $\Delta a_{t}^{s, h}=$ $-\Delta a_{t}^{M, h}\left(1-1 / v_{t}^{D^{b}}\right) p_{t}^{M} / p_{t}^{s}$. When deposits are more (less) liquid than cash then the household sells (buys) security $s$ to (from) the central bank.

\subsection{Multiple Equilibria}

Theorem 1 applies to models with multiple equilibria. Suppose that realizations of a "sunspot" process determine how agents coordinate their behavior; that is, past and present sunspot realizations are an element of the economy's history on which outcomes are conditioned. Theorem 1 implies that any history contingent equilibrium allocation and price system prior to the open-market operation with compensating transfers remains an equilibrium outcome after the intervention as long as the central bank replicates the deposit supply schedule of households and firms. If the central bank does not replicate that schedule, other equilibria may emerge. ${ }^{24}$ In Section 5 , we return to the question of bank-run risk in the context of Central Bank Digital Currency.

\section{Applications}

\subsection{Central Bank Digital Currency and Run Risk}

Would a substitution of Central Bank Digital Currency (CBDC) for bank deposits change the equilibrium allocation? ${ }^{25}$ Plausibly, CBDC would have the same liquidity properties as deposits and a swap therefore would be liquidity neutral. Moreover, the payoff characteristics of CBDC would likely match those of a portfolio of existing securities such

\footnotetext{
${ }^{24}$ For example, rather than letting its pass-through funding replicate run-prone deposit financing from "small" depositors, the central bank could implement a different equilibrium, without contingent bankrun equilibrium allocations, by acting as a large player that internalizes run externalities and avoids runs.

${ }^{25}$ The proposal to make central bank issued digital money accessible to the general public dates back at least to Tobin $(1985,1987)$. For an overview over recent discussions as well as an informal equivalence proposition, see Niepelt (2018, 2020).
} 
that the asset span would remain unchanged. Theorem 1 then implies that an appropriate open-market operation with compensating transfers and a corresponding central bank pass-through policy would not change the equilibrium allocation; and if deposits and $\mathrm{CBDC}$ traded at equal prices, the open-market operation would not require an additional security $s$.

Whether equivalence would require transfers between the private sector and the central bank depends on the payoff characteristics of deposits and CBDC. If the initial equilibrium featured nominally risk free deposits and CBDC were risk free as well then the swap would not change portfolio payoffs and no transfers would be needed. ${ }^{26}$ If, in contrast, deposits bore nominal risk but $\mathrm{CBDC}$ were risk free then equivalence would require new contingent transfers between the private sector and the central bank; these transfers would guarantee that portfolio payoffs (including transfers) in the private sector remained unchanged. ${ }^{27}$

It is frequently argued that CBDC could increase run risk, due to the low cost of withdrawing deposits and transferring them to CBDC accounts, and thereby undermine financial stability. But this neglects the fact that the very act of transferring funds from bank to central bank accounts would amount to an automatic substitution of one type of bank funding (deposits held by households and firms) by another one (central bank funding for banks). By construction, a depositor run for CBDC therefore would not reduce bank funding and undermine financial stability; it would only change the composition of bank funding. ${ }^{28}$

In fact, it seems plausible that the introduction of CBDC could reduce run risk rather than increasing it. After a large swap coupled with pass-through funding, the central bank would become a large, possibly the largest, depositor at private banks. If it pursued an optimal policy (not necessarily the equivalent one) it would internalize the run externalities and might refrain from running itself. As a consequence, the incentives for small depositors to run might also vanish. In addition, CBDC and pass-through funding would bestow the central bank with an informational advantage relative to conventional runs into cash, which the central bank only learns about with a delay. ${ }^{29}$

\subsection{Chicago Plan and "Vollgeld"}

Would an end to fractional reserve banking and thus, a separation of credit and money creation as proposed in the "Chicago Plan" and the Swiss "Vollgeld" initiative change the

\footnotetext{
${ }^{26}$ The risk-free nature of deposits might reflect contingent transfers from the government to banks (e.g., a deposit insurance scheme) and correspondingly, insurance premia that banks pay to the public sector. Under the equivalent arrangement, both these payments would be maintained.

${ }^{27}$ Households and firms thus would pay transfers to the central bank in histories where deposits suffer low returns, for instance because of a bank run. No transfers would be needed if the exposure of households to the government budget exactly mirrored their exposure to risky deposit returns.

${ }^{28}$ If, moreover, the central bank provided funding subject to the same conditions as depositors, then the run would have no allocative effects as shown in Theorem 1.

${ }^{29}$ With CBDC, the central bank could engage more quickly as a lender of last resort; more easily prevent costly fire sales; and better prevent liquidity problems to morph into solvency crises. Small depositors might become less wary themselves which could again reduce run risk. The central bank may also set a low (possibly negative) interest rate on CBDC accounts to render CBDC unattractive as a safe-haven asset.
} 
equilibrium allocation? ${ }^{30}$ Since the Chicago Plan would amount to a complete substitution of CBDC for deposits our discussion of CBDC applies. That is, equivalence would prevail as long as the central bank rather than households and firms supplied deposits to banks, and as long as it did so at the same prices and conditions as in the initial equilibrium.

This, however, is not what the Vollgeld proposal envisioned. According to that proposal, the central bank would not supply deposit substitutes to the banking sector but it would prevent banks from issuing deposits, forcing them to shed assets or seek other sources of funding. Banks would likely loose a source of profits - seignorage rents from liquidity creation - and equivalence would not be guaranteed, both for distributive reasons and because banks might adopt new business models. Equivalence would hold, though, if redistribution between the central bank and the banking sector had no effect on household wealth (e.g., because the economy admitted a representative household or the exposures of households to bank profits and taxes matched each other) and if redistribution did not change bank incentives.

\subsection{Cryptocurrency}

Our framework also is applicable for cryptocurrency-public-money swaps. Clearly, equivalence of such swaps requires the cryptocurrency to operate on a permissioned blockchain with dedicated record keepers. Cryptocurrencies operating based on proof-of-work algorithms require resources, mostly in the form of electricity, to ensure incentive compatibility for record keepers (i.e., miners); since this resource requirement is absent in conventional payment systems equivalence cannot hold for proof-of-work based cryptocurrencies.

If the currency is pegged to the official currency, as many stable coins are, it resembles deposits. With full backing the swap parallels open market operations under a currency board. When the coin and the official currency enter $\mathcal{L}_{t}$-constraints asymmetrically, then the central bank needs to additionally adjust the money supply in order to guarantee equivalence. With less than full backing (fractional reserve banking), coin issuance creates seignorage rents and equivalence thus requires that wealth effects be neutralized by means of taxes and transfers.

If the cryptocurrency's exchange rate is floating, parallel arguments apply. Equivalence additionally requires that return differentials between coins and public money be compensated by contingent transfers. No transfers are needed with a representative household.

\subsection{Indian De-Monetization}

In November 2016, the Indian government decreed that banknotes of larger denomination had to be temporarily deposited in a bank account. ${ }^{31}$ Since the old bank notes were only

\footnotetext{
${ }^{30}$ On the Chicago Plan, see Knight et al. (1933), Fisher (1935, 1936), and Friedman (1960). Benes \& Kumhof (2012) offer a quantitative assessment, arguing that the plan would improve outcomes. The recently rejected Swiss "Vollgeld" initiative proposed a ban on inside money creation. In our discussion, we disregard a key problem of the proposal, namely enforceability.

${ }^{31}$ More than $85 \%$ of cash in circulation were declared illegal tender; banknotes with a denomination of 500 rupees (about $\$ 7.50$ ) or more had to be temporarily deposited. The intervention was designed to
} 
slowly replaced with new ones the intervention increased the stock of digital money. The swap violated the sufficient conditions for our equivalence theorem because transactions in the black economy predominantly require cash.

\section{Conclusions}

Our paper makes four contributions: First, it provides a general framework for the analysis of monetary economies. Second, it derives an asset pricing condition that relates the liquidity of securities to their bubble component and the seignorage rents their issuers reap. Third, it provides sufficient conditions for the equivalence of monetary systems. Theorem 1 should be construed as a benchmark result that helps organize one's thinking, in the spirit of Modigliani \& Miller (1958), Barro (1974), and many other similar findings. The sufficient conditions for equivalence may rarely apply fully; but they clearly identify possible sources of non-equivalence. Finally, we apply our findings in the context of several examples.

Non-equivalence should be expected whenever wealth or liquidity neutrality does not hold or a pass-through policy is ruled out, for instance because the reform has distributive implications and households are sufficiently heterogeneous; many transactions rely on a security that cannot easily be swapped; or transaction costs prevent balance sheet adjustments. Non-equivalence could also be expected when the central bank cannot replicate the private sector's deposit supply schedule, for example due to information frictions. ${ }^{32}$

Another possible impediment to pass-through funding are collateral requirements for lending to banks that differ between private depositors and the central bank (and collateral scarcity). In our theoretical analysis, this issue is not present because we consider a consolidated government with the power to tax depositors. Such a government does not need to impose collateral requirements ex ante in order to guard against losses ex post, unlike an independent central bank that is wary of having to ask for a recapitalization by the fiscal authority in case of losses.

Maybe the most important source of non-equivalence relates to the endogeneity of monetary policy. The equivalence theorem treats policy as exogenous - it does not require the pass through at unchanged conditions to satisfy political incentive compatibility constraints. But this is unrealistic. Even if an intervention satisfied the conditions of Theorem 1, the pass-through policy might well violate political constraints, for instance by rendering implicit transfers in the initial equilibrium explicit, and thus making them better known. ${ }^{33}$

Whether a non-neutral monetary reform would be toward the better or the worse is a question that the equivalence result cannot address. An answer to this question requires an explicit characterization of equilibrium in a particular model. For policy discussions

\footnotetext{
reduce the size of the shadow economy, fight corruption, and remove counterfeited notes from circulation.

${ }^{32}$ In the short run, the information requirement for the central bank appears mild though because deposits and deposit rates tend to be "sticky."

${ }^{33}$ See Niepelt $(2018,2020)$ for a discussion. See Gonzalez-Eiras \& Niepelt (2015) for an analysis of politico-economic equivalence.
} 
about monetary reform, our paper therefore does not propose definite answers, but an analytical framework and robust road map.

\section{A Firms}

Firm $f$ chooses input-output, capital investment, and portfolio sequences to maximize firm value or equivalently, the market value of the firm's dividend stream (Fisher 1930). ${ }^{34}$

We denote firm $f$ 's input or output of commodity $n$ at date $t$ by $y_{t}^{n, f}$; inputs are negative entries, outputs are positive entries. To align with standard "macroeconomic" notation we exclude physical capital holdings, $k_{t}^{f}$, from the commodity vector $y_{t}^{\prime, f}$. We let $\iota_{t}^{n, f}$ denote the quantity of commodity $n$ that firm $f$ uses to produce new physical capital, and $\kappa_{t}^{f}$ the quantity of capital that firm $f$ purchases. The price of physical capital is denoted $q_{t}^{K}$.

When we write $f$ for the type of security then we refer to the equity of firm $f$. E.g., $a_{t}^{f,}$ denotes firm $f$ 's shares outstanding at the end of date $t$, and $z_{t}^{f}$ denotes firm $f$ 's dividends. Without loss of generality we normalize the total shares of each firm to unity.

Letting $\mu_{t, s}$ denote the date- $t$ stochastic discount factor for payoffs at date $s$, firm $f$ chooses $y^{\cdot, f}, \iota^{, f}, \kappa^{f}, k^{f}, a^{\cdot, f}$, and $z^{f}$ to maximize

$$
\begin{aligned}
\sum_{t} \mathbb{E}_{0}\left[\mu_{0, t} z_{t}^{f}\right] \text { s.t. } & \sum_{j \neq f} a_{t}^{j, f} p_{t}^{j}=\sum_{j \neq f} a_{t-1}^{j, f}\left(p_{t}^{j}+z_{t}^{j}\right)+\underbrace{\sum_{n}\left(y_{t}^{n, f}-\iota_{t}^{n, f}\right) q_{t}^{n}-\kappa_{t}^{f} q_{t}^{K}-z_{t}^{f} \forall t,}_{\text {operating profit }} \\
& \mathcal{F}_{t}^{f}\left(k_{t-1}^{f}, y_{t}^{, f}\right) \leq 0 \forall t, \\
& \mathcal{K}_{t}^{f}\left(k_{t-1}^{f}, \iota_{t}^{, f}, \kappa_{t}^{f}, k_{t}^{f}\right) \leq 0 \forall t, \\
& \mathcal{L}_{t}^{f}\left(\left\{a_{t}^{j, f} p_{t}^{j}\right\}_{j},\left\{a_{t-1}^{j, f}\left(p_{t}^{j}+z_{t}^{j}\right)\right\}_{j}, p, y^{,, f}, \iota^{\cdot, f}, \kappa^{f}, q\right) \geq(=) 0 \forall t,
\end{aligned}
$$

and a no-Ponzi game condition.

The first constraint in the firm's program represents the budget constraint. It relates dividend payouts, $z_{t}^{f}$, to the firm's operating profit and accumulation of net financial assets. The second and third constraints represent production constraints; function $\mathcal{F}_{t}^{f}$ represents the firm's production possibilities and function $\mathcal{K}_{t}^{f}$ represents the law of motion for physical capital, possibly accounting for depreciation and adjustment costs (Jorgensen 1963, Tobin 1969, Hayashi 1982). ${ }^{35}$ The $\mathcal{L}_{t}^{f}$-constraint parallels the $\mathcal{L}_{t}^{h}$-constraint of a

\footnotetext{
${ }^{34}$ The optimal timing of dividend payouts is indeterminate (Modigliani \& Miller 1958).

${ }^{35}$ We could merge the law of motion for capital and the budget constraint. Suppose for example that the law of motion takes the form

$$
k_{t}^{f}=k_{t-1}^{f}(1-\delta)+\Phi\left(\iota_{t}^{, f}, k_{t-1}^{f}\right)+\kappa_{t}^{f},
$$

where $\delta$ denotes the depreciation rate and $\Phi\left(\iota_{t}, f, k_{t-1}^{f}\right)$ denotes physical capital generated from investment $i_{t}^{, f}$, possibly subject to adjustment costs. The budget constraint can then be written as

$$
\sum_{j \neq f} a_{t}^{j, f} p_{t}^{j}+k_{t}^{f} q_{t}^{K}=\sum_{j \neq f} a_{t-1}^{j, f}\left(p_{t}^{j}+z_{t}^{j}\right)+k_{t-1}^{f}(1-\delta) q_{t}^{K}+\sum_{n}\left(y_{t}^{n, f}-\iota_{t}^{n, f}\right) q_{t}^{n}+\Phi\left(\iota_{t}^{\cdot, f}, k_{t-1}^{f}\right) q_{t}^{K}-z_{t}^{f}
$$
}


household; it captures restrictions that relate to the medium-of-exchange function of securities or other financial frictions.

To accommodate price rigidity à la Calvo (1983) we could augment the firm's program by a condition that reflects monopolistic competition in the firm's output market (Dixit \& Stiglitz 1977). This condition would relate demand for the firm's output to the price set by the firm (which would constitute an additional choice variable) as well as to choices made by other firms. The structure of the constraint would parallel the structure of the limited competition constraint that we discuss in the context of the bank's program. Introducing such a constraint in the firm's program would not affect our results because securities do not enter the constraint.

\section{B Liquidity Neutrality}

Consider the following condition:

Condition 1. For all $i \in \mathbb{I}$, the one-period swap with agents $i \in \mathbb{I}$ at date $t$ and the functions $\mathcal{L}_{t}^{i}$ and $\mathcal{L}_{t+1}^{i}$ satisfy:

1. $a_{t}^{M, i}$ and $a_{t}^{D^{b}, i}$ are linearly substitutable,

$$
\begin{aligned}
\mathcal{L}_{t}^{i}\left(\left\{a_{t}^{j, i} p_{t}^{j}\right\}_{j},\left\{a_{t-1}^{j, i}\left(p_{t}^{j}+z_{t}^{j}\right)\right\}_{j}, p, x^{,, i}, q\right) & =\hat{\mathcal{L}}_{t}^{i}\left(A_{t, t}^{i}, \Phi_{t}^{i}\right), \\
\mathcal{L}_{t+1}^{i}\left(\left\{a_{t+1}^{j, i} p_{t+1}^{j}\right\}_{j},\left\{a_{t}^{j, i}\left(p_{t+1}^{j}+z_{t+1}^{j}\right)\right\}_{j}, p, x^{,, i}, q\right) & =\hat{\mathcal{L}}_{t+1}^{i}\left(A_{t+1, t}^{i}, \Psi_{t+1}^{i}\right) \forall t+1 \mid t,
\end{aligned}
$$

where $\Phi_{t}^{i}, \Psi_{t+1}^{i} \perp a_{t}^{M, i}, a_{t}^{D^{b}, i}$ and

$$
\begin{aligned}
A_{t, t}^{i} & \equiv a_{t}^{M, i} p_{t}^{M} v_{t}^{M}+a_{t}^{D^{b}, i} p_{t}^{D^{b}} v_{t}^{D^{b}}, \\
A_{t+1, t}^{i} & \equiv a_{t}^{M, i}\left(p_{t+1}^{M}+z_{t+1}^{M}\right) v_{t+1}^{M}+a_{t}^{D^{b}, i}\left(p_{t+1}^{D^{b}}+z_{t+1}^{D^{b}}\right) v_{t+1}^{D^{b}},
\end{aligned}
$$

for some exogenous "velocity" parameters $v_{t}^{M}, v_{t}^{D^{b}}, v_{t+1}^{M}, v_{t+1}^{D^{b}} \neq 0$;

2. the liquidity effects of $\Delta a_{t}^{M, i}$ and $\Delta a_{t}^{D^{b}, i}$ offset each other,

$$
\begin{aligned}
p_{t}^{M} v_{t}^{M} \Delta a_{t}^{M, i}+p_{t}^{D^{b}} v_{t}^{D^{b}} \Delta a_{t}^{D^{b}, i} & =0 \\
\left(p_{t+1}^{M}+z_{t+1}^{M}\right) v_{t+1}^{M} \Delta a_{t}^{M, i}+\left(p_{t+1}^{D^{b}}+z_{t+1}^{D^{b}}\right) v_{t+1}^{D^{b}} \Delta a_{t}^{D^{b}, i} & =0 \forall t+1 \mid t .
\end{aligned}
$$

If a one-period swap satisfies the second part of Condition 1 then it leaves $A_{t, t}^{i}, A_{t+1, t}^{i}$, $\Phi_{t}^{i}$, and $\Psi_{t+1}^{i}$ unchanged for all $i \in \mathbb{I}$. From the first part of Condition 1 the swap then leaves the function values $\mathcal{L}_{t}^{i}$ and $\mathcal{L}_{t+1}^{i}$ and the derivatives unchanged as well. We thus have the following result:

Lemma 2 (Liquidity Neutrality). Under Condition 1, a one-period swap with agents $i \in \mathbb{I}$ at date $t$ is liquidity neutral (conditional on commodity prices, security prices, and fundamental payoffs). 


\section{References}

Andolfatto, D. (2018), Reconciling orthodox and heterodox views on money and banking, Working Paper 2018-27A, Federal Reserve Bank of St. Louis, St. Louis.

Barro, R. J. (1974), 'Are government bonds net wealth?', Journal of Political Economy 82(6), 1095-1117.

Baumol, W. J. (1952), 'The transactions demand for cash', Quarterly Journal of Economics $67(4)$, 545-556.

Benes, J. \& Kumhof, M. (2012), The Chicago plan revisited, Working Paper 12/202, International Monetary Fund, Washington.

Bewley, T. F. (1980), The optimum quantity of money, in J. H. Kareken \& N. Wallace, eds, 'Models of Monetary Economies', Federal Reserve Bank of Minneapolis, Minneapolis, pp. 169-210.

Brunnermeier, M. K. \& Sannikov, Y. (2016), The I theory of money, Working Paper 22533, NBER, Cambridge, Massachusetts.

Bryant, J. (1983), 'Government irrelevance results: A simple exposition', American Economic Review 73(4), 758-761.

Calomiris, C. W. \& Kahn, C. M. (1991), 'The role of demandable debt in structuring optimal banking arrangements', American Economic Review 81(3), 497-513.

Calvo, G. A. (1983), 'Staggered prices in a utility-maximizing framework', Journal of Monetary Economics 12(3), 383-398.

Chamley, C. \& Polemarchakis, H. (1984), 'Assets, general equilibrium and the neutrality of money', Review of Economic Studies 51(1), 129-138.

Clarida, R., Galí, J. \& Gertler, M. (1999), 'The science of monetary policy: A New Keynesian perspective', Journal of Economic Literature 37(4), 1661-1707.

Clower, R. W. (1967), 'A reconsideration of the microfoundations of monetary theory', Western Economic Journal 6(1), 1-8.

Croushore, D. (1993), 'Money in the utility function: Functional equivalence to a shoppingtime model', Journal of Macroeconomics 15(1), 175-182.

Diamond, D. W. \& Rajan, R. G. (2001), 'Liquidity risk, liquidity creation, and financial fragility: A theory of banking', Journal of Political Economy 109(2), 287-327.

Dixit, A. K. \& Stiglitz, J. E. (1977), 'Monopolistic competition and optimum product diversity', American Economic Review 67(3), 297-308. 
Faure, S. \& Gersbach, H. (2018), Money creation in different architectures, Discussion Paper 13156, CEPR.

Feenstra, R. C. (1986), 'Functional equivalence between liquidity costs and the utility of money', Journal of Monetary Economics 17(2), 271-291.

Fisher, I. (1930), The Theory of Interest, as determined by Impatience to Spend Income and Opportunity to Invest it, Macmillan, New York.

Fisher, I. (1935), 100\% Money, Adelphi, New York.

Fisher, I. (1936), '100\% money and the public debt', Economic Forum (April-June), 406420.

Friedman, M. (1960), A Program for Monetary Stability, Fordham University Press, New York.

Friedman, M. (1969), The optimum quantity of money, in M. Friedman, ed., 'The Optimum Quantity of Money and Other Essays', Aldine, Chicago, chapter 1, pp. 1-50.

Galí, J. (2008), Monetary Policy, Inflation, and the Business Cycle, Princeton University Press, Princeton.

Gonzalez-Eiras, M. \& Niepelt, D. (2015), 'Politico-economic equivalence', Review of Economic Dynamics 18(4), 843-862.

Grandmont, J.-M. \& Younes, Y. (1972), 'On the role of money and the existence of a monetary equilibrium', Review of Economic Studies 39(3), 355-372.

Gurley, J. G. \& Shaw, E. S. (1960), Money in a Theory of Finance, Brookings Institution, Washington.

Hayashi, F. (1982), 'Tobin's marginal q and average q: A neoclassical interpretation', Econometrica 50(1), 213-224.

Holmström, B. \& Tirole, J. (1998), 'Private and public supply of liquidity', Journal of Political Economy 106(1), 1-40.

Holmström, B. \& Tirole, J. (2001), 'LAPM: A liquidity-based asset pricing model', Journal of Finance 56(5), 1837-1867.

Jorgensen, D. W. (1963), 'Capital theory and investment behavior', American Economic Review, Papers and Proceedings 53(2), 247-259.

Kiyotaki, N. \& Moore, J. (2012), Liquidity, business cycles, and monetary policy, Working Paper 17934, NBER, Cambridge, Massachusetts.

Kiyotaki, N. \& Wright, R. (1993), 'A search-theoretic approach to monetary economics', American Economic Review 83(1), 63-77. 
Knight, F. H., Cox, G. V., Director, A., Douglas, P. H., Fisher, I., Hart, A. G., Mints, L. W., Schultz, H. \& Simons, H. C. (1933), Memorandum on banking reform. Henry C. Wallace papers.

Lagos, R. (2010), 'Asset prices and liquidity in an exchange economy', Journal of Monetary Economics 57(8), 913-930.

Lagos, R. \& Wright, R. (2005), 'A unified framework for monetary theory and policy analysis', Journal of Political Economy 113(3), 463-484.

Lucas, R. E. (1980), Equilibrium in a pure currency economy, in J. H. Kareken \& N. Wallace, eds, 'Models of Monetary Economies', Federal Reserve Bank of Minneapolis, Minneapolis, pp. 131-145.

Lucas, R. E. (1982), 'Interest rates and currency prices in a two-country world', Journal of Monetary Economics 10(3), 335-359.

Lucas, R. E. \& Stokey, N. L. (1987), 'Money and interest rates in a cash-in-advance economy', Econometrica 55(3), 491-513.

McCallum, B. T. \& Goodfriend, M. S. (1987), Demand for money: Theoretical studies, in J. Eatwell, P. Newman \& M. Milgate, eds, 'The New Palgrave: A Dictionary of Economics', Macmillan Press, London, pp. 775-781.

Modigliani, F. \& Miller, M. H. (1958), 'The cost of capital, corporation finance and the theory of investment', American Economic Review 48(3), 261-297.

Niepelt, D. (2018), Reserves for all? Central Bank Digital Currency, deposits, and their (non)-equivalence, Discussion Paper 13065, CEPR.

Niepelt, D. (2020), 'Reserves for all? Central Bank Digital Currency, deposits, and their (non)-equivalence', International Journal of Central Banking forthcoming.

Rocheteau, G. \& Nosal, E. (2017), Money, Payments, and Liquidity, 2. edn, MIT Press, Cambridge, Massachusetts.

Samuelson, P. A. (1958), 'An exact consumption-loan model of interest with or without the social contrivance of money', Journal of Political Economy 66(6), 467-482.

Sargent, T. J. (1987), Dynamic Macroeconomic Theory, Harvard University Press, Cambridge, Massachusetts.

Saving, T. R. (1971), 'Transactions costs and the demand for money', American Economic Review 61(3), 407-420.

Shell, K. (1971), 'Notes on the economics of infinity', Journal of Political Economy $79(5), 1002-1011$. 
Sidrauski, M. (1967), 'Rational choice and patterns of growth in a monetary economy', American Economic Review 57(2), 534-544.

Svensson, L. E. O. (1985), 'Money and asset prices in a cash-in-advance economy', Journal of Political Economy 93(5), 919-944.

Tobin, J. (1956), 'The interest elasticity of the transactions demand for cash', Review of Economics and Statistics 38(3), 241-247.

Tobin, J. (1963), Commercial banks as creators of "money", Discussion Paper 159, Cowles Foundation, New Haven.

Tobin, J. (1969), 'A general equilibrium approach to monetary theory', Journal of Money, Credit, and Banking 1(1), 15-29.

Tobin, J. (1985), 'Financial innovation and deregulation in perspective', Bank of Japan Monetary and Economic Studies 3(2), 19-29.

Tobin, J. (1987), The case for preserving regulatory distinctions, in 'Restructuring the Financial System, Proceedings of the Economic Policy Symposium, Jackson Hole', Federal Reserve Bank of Kansas City, Kansas City, chapter 9, pp. 167-183.

Townsend, R. M. (1980), Models of money with spatially separated agents, in J. H. Kareken \& N. Wallace, eds, 'Models of Monetary Economies', Federal Reserve Bank of Minneapolis, Minneapolis, pp. 265-304.

Wallace, N. (1980), The overlapping generations model of fiat money, in J. H. Kareken \& N. Wallace, eds, 'Models of Monetary Economies', Federal Reserve Bank of Minneapolis, Minneapolis, pp. 49-82.

Wallace, N. (1981), 'A Modigliani-Miller theorem for open-market operations', American Economic Review 71(3), 267-274.

Woodford, M. (1990), 'Public debt as private liquidity', American Economic Review 80(2), 382-388.

Woodford, M. (2003), Interest and Prices, Princeton University Press, Princeton. 